\title{
Natural AD-Like Neuropathology in Octodon degus: Impaired Burrowing and Neuroinflammation
}

\author{
Robert M.J. Deacon ${ }^{1,5}$, Francisco J. Altimiras ${ }^{1}$, Enrique A. Bazán-León ${ }^{2}$, Rhada D. Pyarasani ${ }^{3}$, \\ Fabiane M. Nachtigall ${ }^{3}$, Leonardo S. Santos ${ }^{3}$, Anthony G. Tsolaki ${ }^{4}$, Lina Pednekar ${ }^{4}$, Uday Kishore ${ }^{4}$, \\ Rodolfo R. Biekofsky ${ }^{5}$, Rodrigo A. Vásquez ${ }^{2}$ and Patricia Cogram ${ }^{1,5, *}$
}

\begin{abstract}
${ }^{I}$ Biomedicine Division, Center for Systems Biotechnology, Fraunhofer Chile Research Foundation, Santiago, Chile; ${ }^{2}$ Instituto de Ecología y Biodiversidad, Departamento de Ciencias Ecológicas, Facultad de Ciencias, Universidad de Chile, Santiago, Chile; ${ }^{3}$ Laboratory of Asymmetric Synthesis, Chemistry Institute of Natural Resources, Nanobiotechnology Division, University of Talca, Fraunhofer Chile Research Foundation, Center for Systems Biotechnology, Talca, Chile; ${ }^{4}$ Centre for Infection, Immunity and Disease Mechanisms, Biosciences, Heinz Wolff Building, Brunel University, London, UK; ${ }^{5}$ NEURO-DVI LLP, London, UK
\end{abstract}

\begin{abstract}
Alzheimer's disease (AD) is the most common cause of dementia, affecting more than 36 million people worldwide. Octodon degus, a South American rodent, has been found to spontaneously develop neuropathological signs of $\mathrm{AD}$, including amyloid- $\beta(\mathrm{A} \beta)$ and tau deposits, as well as a decline in cognition with age. Firstly, the present work introduces a novel behavioral assessment for $O$. degus - the burrowing test - which appears to be a useful tool for detecting neurodegeneration in the $O$. degus model for AD. Such characterization has potentially wide-ranging implications, because many of these changes in species-typical behaviors are reminiscent of the impairments in activities of daily living (ADL), so characteristic of human AD. Furthermore, the present work characterizes the ADlike neuropathology in $O$. degus from a gene expression point of view, revealing a number of previously unreported AD biomarkers, which are found in human AD: amyloid precursor protein (APP), apolipoprotein E (ApoE), oxidative stressrelated genes from the NFE2L2 and PPAR pathway, as well as pro-inflammatory cytokines and complement proteins, in agreement with the known link between neurodegeneration and neuroinflammation. In summary, the present results confirm a natural neuropathology in $O$. degus with similar characteristics to $\mathrm{AD}$ at behavioral, cellular and molecular levels. These characteristics put $O$. degus in a singular position as a natural rodent model for research into AD pathogenesis and therapeutics against AD.
\end{abstract}

Keywords: Alzheimer's disease, beta-amyloid, burrowing, complement, cytokines, Octodon degus.

\section{INTRODUCTION}

Alzheimer's disease (AD) is the most common form of dementia associated with age, affecting approximately 36 million people worldwide. Its incidence is rising as the average age of the population increases, and it is estimated that by 2050, the number of cases will rise to 110 million [1-2]. Thus, AD represents a critical health problem worldwide [3-4].

Over the last two decades, several transgenic animal models have been developed for elucidating the mechanistic aspects of $\mathrm{AD}$ and validating potential therapeutic targets. However, the transgenic models of AD cannot fully establish all of the pathological features in the evolution of the disease [5-6]. A basic problem for the transgenic animal models has been the assumption that once genes that generate amyloid- $\beta$ (A $\beta$ ) peptides have been modified, a clinically representative animal model for $\mathrm{AD}$ has been established.

*Address correspondence to this author at the Biomedicine Division, Center for Systems Biotechnology, Fraunhofer Chile Research Foundation, Santiago, Chile; Tel: +56 2 2378-1650; E-mails: pcogram@fraunhofer.cl; patricia.cogram@gmail.com
Octodon degus, a small rodent endemic to central Chile [7-8] has been found to spontaneously develop neuropathological signs of $\mathrm{AD}$, including $\mathrm{A} \beta$ oligomers and tau deposits; cognition also declines as the animals grow older [9$11]$. Recent evidence strongly supports the hypothesis that $O$. degus provides a natural model for the study of the early neurodegenerative processes associated with sporadic AD, and therefore should be used as a general model for academic research and companies involved with AD [12].

The present work introduces a novel behavioral assessment for $O$. degus, the burrowing test - a species typical behavior - that exploits a common natural rodent behavior, provides quantitative data under controlled laboratory conditions, and has proved extremely sensitive to degenerative diseases, drug administration, strain differences, and brain lesions [13-19]. Burrowing is a simple, cheap, easy to measure and objective ethological measure [19-22]. Burrowing is used in this work in order to distinguish healthy from ADlike $O$. degus, introducing a novel behavioral approach to preclinical screening in AD.

The present work also investigates the gene expression profile for the $\mathrm{AD}$-like neuropathology in $O$. degus and its 
correlation with human $\mathrm{AD}$. In particular, cytokines and other pro-inflammatory signaling molecules affected in the AD-like neuropathology were investigated, highlighting the validity of the $O$. degus model from a neuroinflammatory perspective on $\mathrm{AD}$ [23-26].

Overall, the present work validates $O$. degus as a natural animal model for AD. Further understanding of the ensemble of neurodegenerative mechanisms might hold the key to the pathogenesis of $\mathrm{AD}$, and thus to new pharmacotherapies.

\section{MATERIALS AND METHODS}

\section{Animals}

Male and female Octodon degus (Rodentia: Octodontidae) $(\mathrm{n}=84)$ were captured from a natural population in central Chile at Rinconada de Maipú, $30 \mathrm{~km}$ west of Santiago. Animals, 3-6 months old, were caught with Sherman live traps. They were housed in standard metal cages $50 \mathrm{x}$ $40 \times 35 \mathrm{~cm}$ with a layer of wood shaving as bedding and containing a small metallic box $(25 \times 15 \times 10 \mathrm{~cm}$ with a single entrance), under natural photoperiod, in an airconditioned animal room at the University of Chile. They were fed with rabbit pellets and alfalfa and provided water ad libitum during the entire experimental period. All procedures of capture, transportation, maintenance and experimentation followed the recommendations of the ethics committee of the Faculty of Sciences of the University of Chile, and complied with Chilean regulations (ServicioAgrícola y Ganadero - SAG) as well as recommendations by the Animal Behavior Society. A set of three-year old animals was used in the experiments

\section{O. degus Burrowing}

\section{Apparatus}

Each burrow was a $30 \mathrm{~cm}$ long grey plastic cylinder, $10.5 \mathrm{~cm}$ diameter. To minimize non-deliberate displacement of food pellets, the open end of the tube was raised 5 $\mathrm{cm}$ by bolting two $50 \mathrm{~mm}$ machine screws under it, $1 \mathrm{~cm}$ in from one end, spaced just less than a quadrant of the tube apart, protruding like the undercarriage of a small aircraft. The lower end of the tube was closed with a grey plastic plug, fitted with two screws to bolt the tube to the end of the cage using wing nuts (to prevent the animals moving the burrow).

\section{Procedure}

The burrowing test was used as developed by Deacon [19]. Each burrow was filled with $800 \mathrm{~g}$ food pellets (rabbit diet pellets that the $O$. degus were used to eating, to avoid inducing any anxiety or neophobia) and placed in a clean cage with a thin layer of bedding, a water bottle but no cage furniture. Each trial started at 9-10 am approximately, at the beginning of the diurnal normal activity cycle of $O$. degus [27]. After $2 \mathrm{~h}$, the weight (in grams) of food displaced from the burrow was calculated. The test continued for another 4 $\mathrm{h}$, making $6 \mathrm{~h}$ in total. The $2 \mathrm{~h}$ and $6 \mathrm{~h}$ measures were compared separately, using nonparametric pair wise good vs. poor burrower group comparisons $(n=20)$, and the results expressed as medians, with the variability shown by the interquartile range (IQR).

\section{MALDI-TOF MS Analysis}

\section{Tissue Collection}

Harvesting of the organ or tissue was performed in accordance with the appropriate local ethical guidelines. The tissue was frozen directly in liquid nitrogen after dissection and stored at $-80{ }^{\circ} \mathrm{C}$ until use.

\section{Sample Preparation}

Four frozen $O$. degus brains from each group (see Fig. 1) were sectioned into right and left hemispheres using a surgical blade. The obtained section was homogenized in $2 \mathrm{ml}$ of ultrapure water by ultrasonication for $4 \mathrm{~h}$. The supernatant liquid was isolated and lyophilized to obtain the solid sample. This was re-suspended in $200 \mu 1$ of $0.1 \%$ TFA solution and centrifuged at $3000 \mathrm{rpm}$ for $10 \mathrm{~min}$ to obtain the concentrated sample.

\section{Matrix Solution Preparation}

$\alpha$-cyano-4-hydrocinnamic acid was employed as matrix, which is appropriate for peptide masses $<10 \mathrm{kDa}$. To the freshly prepared $1.5 \mu 1$ of the $\alpha$-cyano-4-hydroxycinnamic acid matrix solution, the sample solution was mixed in a microfuge tube, vortexed well and deposited directly on to the MALDI plate and left to air dry.

\section{Ionization and Detection}

The peak for the $A \beta_{1-42}$ peptide was assigned based on matching the measured molecular mass of the peak with the calculated molecular mass of $\mathrm{A} \beta_{1-42}$ peptide based on the $O$. degus $\mathrm{A} \beta_{1-42}$ amino acid sequence. Normal processing of the mass spectra included smoothing of the local linear baseline subtraction and nonlinear regression peak fitting with a Lorentzian peak shape for quantification according to Bruker Data Analysis 4.0 Software.

\section{RT-qPCR Procedure \\ RNA Extraction}

Samples were obtained from full brain samples. The samples were immediately frozen in liquid nitrogen and conserved at $-80^{\circ} \mathrm{C}$ prior to use. Pure LinkTM RNA Mini kit (Ambion, Life Technologies) was used for total RNA extraction, according to the manufacturer's instructions. Total RNA samples were quantified by spectrophotometry in a Nanodrop instrument and integrity was evaluated by agarose gels electrophoresis with a standard protocol.

\section{cDNA Synthesis}

For cDNA synthesis, $1 \mu \mathrm{g}$ of the total RNA was incubated for 5 minutes at $65^{\circ} \mathrm{C}$ with $40 \mu \mathrm{M}$ of oligo-dT, $2.5 \mathrm{mM}$ of each dNTP and DEPC-treated water to a final volume of $16 \mu \mathrm{L}$. Then, a mix containing 200 units of M-MuLV reverse transcriptase (New England BioLabs), 10 U RNAase inhibitor and DEPC-treated water (to final volume of $20 \mu \mathrm{L}$ ) was added followed by incubation at $55^{\circ} \mathrm{C}$ for 60 minutes. Then cDNAs were quantified and stored at $-20^{\circ} \mathrm{C}$.

\section{qPCR Procedure}

Primer sequences for each gene target were designed and analyzed for specificity using the nucleotide BLAST and 
Table 1. Real-Time quantitative PCR primer sequences and Octodon degus gene targets.

\begin{tabular}{|c|c|c|}
\hline Gene & Forward Primer & Reverse Primer \\
\hline 18S rRNA & ATGGCCGTTCTTAGTTGGTG & CGCTGAGCCAGTCAGTGTAG \\
\hline IL-1及 & TCTTTGAAGTCGATGGCCCC & CTCAAGTCGCCATCCTGGAA \\
\hline IL-6 & CTCGTGAAACCTGAGGCCAA & CTCCCCATTTGACTCCGCAT \\
\hline TNF- $\alpha$ & AAGCCTGTAGCTCACGTTGT & GTGAGCAGCAGGTAGGAGTG \\
\hline GM-CSF & GACCCAGCTGCTGTGATGAA & AGGAAGTTTCTGGGGTTGGC \\
\hline IFN- $\alpha$ & ACAAATGAGGAGAATCTCCACTTT & CTCCTGGGTCAGGCAGGCC \\
\hline C1q & AGCAGCCAAAGAAGGTGGTT & CACACATCCACATCGGGGAA \\
\hline $\mathbf{C 3}$ & CACTCAGGAGGCTGACGTTT & CAACCTGTCCAGCATGGCTA \\
\hline $\mathrm{C} 4$ & CCCAGGTTGCTTCTTTTCGC & GCTGAGGAGCTGGAAGTCTC \\
\hline $\mathbf{C 5}$ & GATCGAGCAGTGGATTGGCT & GATGACTCCTCCTTGCTCGG \\
\hline C9 & ACAATGGTGACACAAGCCGA & AGAGTGTTTCCACCCCAAGC \\
\hline CFH & AATGGAGTTCACCGCCTGAG & AGACTGGTGGAGTGGACCAT \\
\hline CFP & TGCAACACAACTGTGCCTTG & AGCAGTGTCGGATTTCCTGG \\
\hline APOE & GTCACGCTTCTGGCAGGAT & GTCAGTTCCTGGGTGACCTG \\
\hline APP & TCCAGCCATGGCATCCTTTT & ATACCCTGAGTCGTGTCGGA \\
\hline NFE2L2 & CTTGGGGCAAGTCGAGAAGT & TGACTGGATGTGCTGAGCTG \\
\hline PPARa & GAGAGCCCCCTGTCTGAGTA & GGGTAAATGACGGAGGACGG \\
\hline
\end{tabular}

Primer-BLAST (http://blast.ncbi.nlm.nih.gov/Blast.cgi) (Table 1). The qPCR reaction consisted of $5 \mu$ l Power SYBR Green MasterMix (Applied Biosystems), 75nM of forward and reverse primer and 500ng template cDNA in a $10 \mu$ final reaction volume. PCR was performed on a 7900HT Fast Real-Time PCR System (Applied Biosystems). The initiation steps involved $2^{\prime}$ at $50^{\circ} \mathrm{C}$ followed by $10^{\prime}$ at $95^{\circ} \mathrm{C}$. The template was then amplified for 40 cycles, each cycle comprised of $15 \mathrm{sec}$ at $95^{\circ} \mathrm{C}$ and $1^{\prime}$ at $60^{\circ} \mathrm{C}$.

Samples were normalized using the expression of human 18S rRNA. Data was analyzed using the RQ Manager Version 1.2.1 (Applied Biosystems). Ct (cycle threshold) values for each target gene were calculated and the relative expression of each target gene was calculated using the Relative Quantification (RQ) value, using the equation: $R Q=2^{-\Delta \Delta C t}$ for each target gene, and comparing relative expression with that of the $18 \mathrm{~S}$ rRNA constitutive gene product. Assays were conducted in triplicate. Error bars represent \pm standard error of the mean. Data represents 4 "good burrower" $O$. degus and 4 "poor burrower" O. degus samples (see Fig. 1). An unpaired, two-tailed t-test was performed on the data and significant differences in expression between good burrowers and poor burrower's samples are shown as follows: $* \mathrm{P}=<0.05$, and $* * \mathrm{P}=\leq 0.01$.

\section{Statistical Analysis}

Statistical analysis was performed using GraphPad Prism version 6.0 (GraphPad Software). An unpaired 2-tailed t-test was used to compare the means of the transcript targets for "good burrower" $O$. degus (control) and "poor burrower" $O$. degus (AD-like) samples for any significant difference in expression. $\mathrm{P}$ values were computed and graphs compiled and analyzed.

\section{RESULTS}

\section{Burrowing Performance Inversely Correlates with $\beta$ - Amyloid Load}

Burrowing performance was evaluated in a group of three-year-old $O$. degus for two and six hours from the start of the test (Fig. 1). The two-hour measurement appears to be more sensitive than the six-hour one; the latter measurement often suffers from a ceiling effect, as many animals will burrow the entire tube contents. Nearly $50 \%$ of $O$. degus were able to empty the burrow, whereas $30 \%$ of $O$. degus were unable to remove more than $50 \mathrm{~g}$ of pellets. A statistical difference with a $\mathrm{p}$ value $<0.0001$ was found for $2 \mathrm{~h}$ and $6 \mathrm{~h}$ time points, using nonparametric pair wise comparison between good and poor burrower groups.

Based on their burrowing capacity, two clearly distinct groups were identified: those animals that performed well (the "good burrowers") and those that performed badly (the "poor burrowers"). In agreement with these results, a previous study showed great intra-population variability in learning capabilities in two-year old O. degus [28].

The presence of amyloid in the brain was determined by MALDI-TOF-MS in these two groups of O. degus. The 
presence of $A \beta_{1-42}$ peptide signal at $\mathrm{m} / z 4536$ in the brains of the poor burrowers is an indication of amyloid in those animals which showed impairment in displacing food material at $2 \mathrm{~h}$ and $6 \mathrm{~h}$ (Fig. 2).

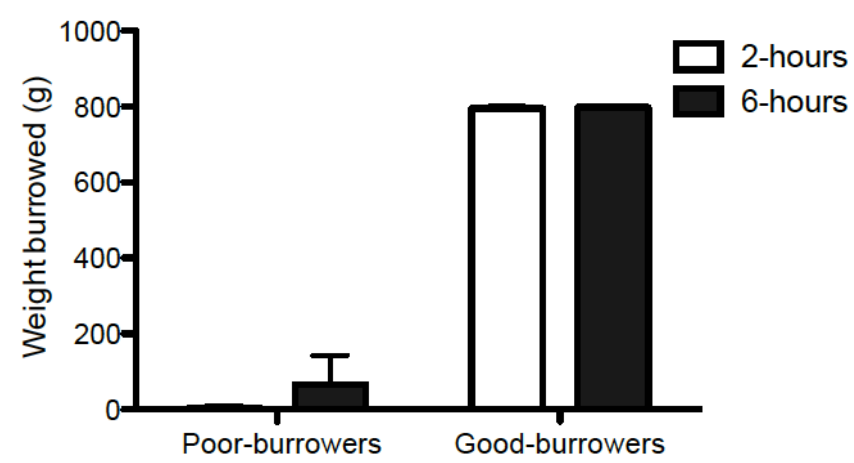

Fig. (1). Burrowing performance in $O$. degus. Measurements were taken at 2 and $6 \mathrm{~h}$ on two separate occasions for each animal. Values are medians \pm IQR.
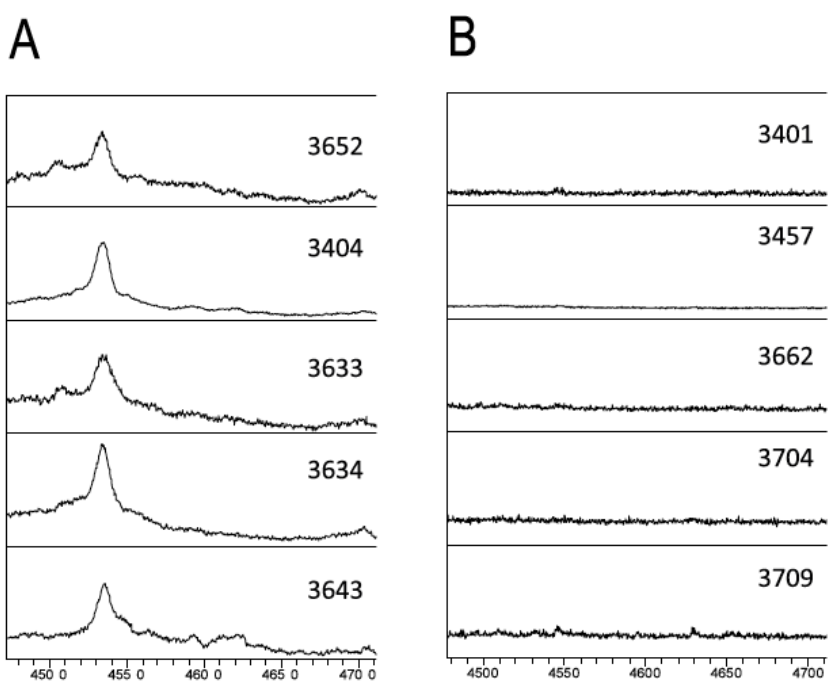

Fig. (2). MALDI-MS profiles of $\mathrm{A} \beta_{1-42}$ peptide in $O$. degus brains: (A) representative spectra showing the presence of $A \beta_{1-42}$ peptide with a $m / z 4536 \mathrm{Da}$ in worst poor burrowers (PB) (positives); (B) representative spectra showing the absence of $A \beta_{1-42}$ peptide around $\mathrm{m} / \mathrm{z} 4536 \mathrm{Da}$ in best good burrowers (GB) (negatives).

\section{Gene Expression Profile in Three-Year-Old O. degus}

Gene expression profiles of apolipoprotein E (ApoE), amyloid precursor protein (APP), peroxisome proliferatoractivated receptor alpha (PPARa), and Nuclear Factor (erythroid-derived 2)-Like 2 (NFE2L2) were analyzed for the two groups of O. degus. As shown in Fig. (3), ApoE, APP and NFE2L2 (or Nrf2) were significantly up-regulated in poor burrowers compared to their good burrower control. This finding supports the hypothesis that dysregulation of ApoE and APP may contribute to accumulation of $A \beta_{1-42}$ in the AD rodent model (poor burrower). This also is seen in the Nrf2 gene expression profile in which the lack in mRNA levels of one of the key mediators of the oxidative stress response was observed (Fig. 3). Further analysis of other genes such as Presinilins 1 and 2, APP variants and PPAR may provide further key points of AD-like neuropathology in the $O$. degus helping to identify possible pharmacological targets which may delay the progress of the disease and the effects of amyloid oligomer neurotoxicity.
APOE
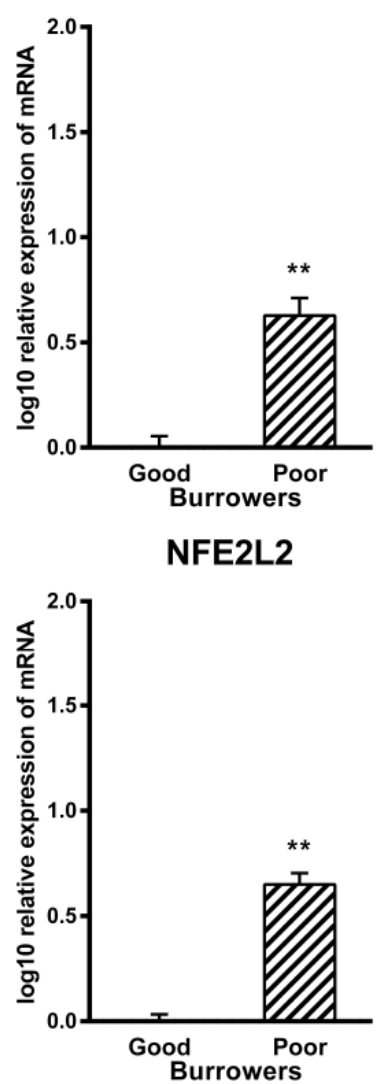

APP
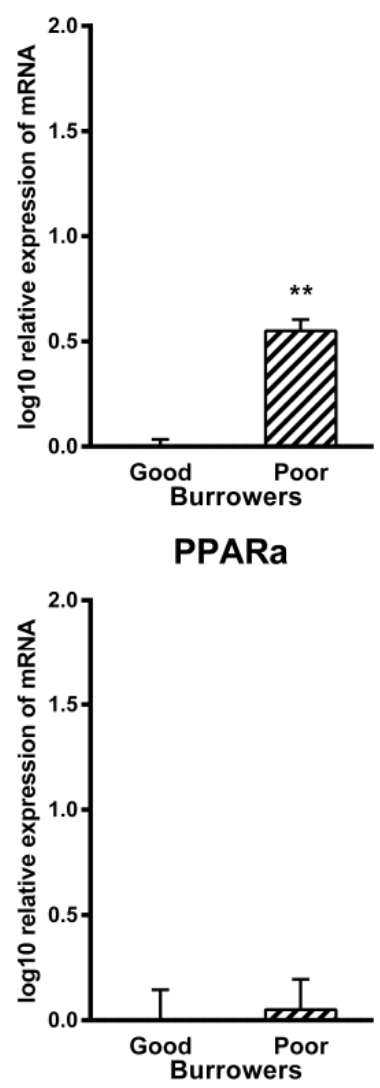

Fig. (3). Expression profile of $\mathrm{AD}$ marker genes in the $O$. degus model. Expression was measured using real time qPCR and the data normalized to $18 \mathrm{~S}$ rRNA gene expression as an endogenous control. Relative expression (RQ) was calculated by using the comparative Ct method with 'Control' $O$. degus (good burrower) samples used as the calibrator. The RQ value was calculated using the formula: $\mathrm{RQ}=2^{-\Delta \Delta \mathrm{Ct}}$. Assays were conducted in triplicate. Error bars represent \pm standard error of the mean. Data represents $O$. degus 'good burrowers' $(\mathrm{n}=4)$ and $O$. degus 'poor burrowers' $(\mathrm{n}=4)$. An unpaired, two-side t-test was performed on the data and significant differences in expression between 'good burrower' and 'poor burrower' ('Control' and 'AD-like') samples are shown as follows: all time points showed no significant differences in expression, $\mathrm{p} \geq 0.05$, except where shown significant, *: $0.01<\mathrm{p}<0.05$, and $* *: \mathrm{p} \leq 0.01$.

The differential expression of a number of proinflammatory cytokines between 'good' and 'poor burrower' were also examined. The levels of IL- 6 , IFN- $\alpha$, TNF- $\beta$ and GM-CSF, presented in Fig. (4), were considerably higher in poor burrower (AD-like) compared to good burrower (control) animals. Compared to the pro-inflammatory cytokines mentioned above, IL-1 $\beta$ was slightly but significantly upregulated in poor burrowers.

Given the role of complement proteins in neuroinflammation in $\mathrm{AD}$ and in other neurodegenerative disease, we also examined if complement proteins, especially classical 

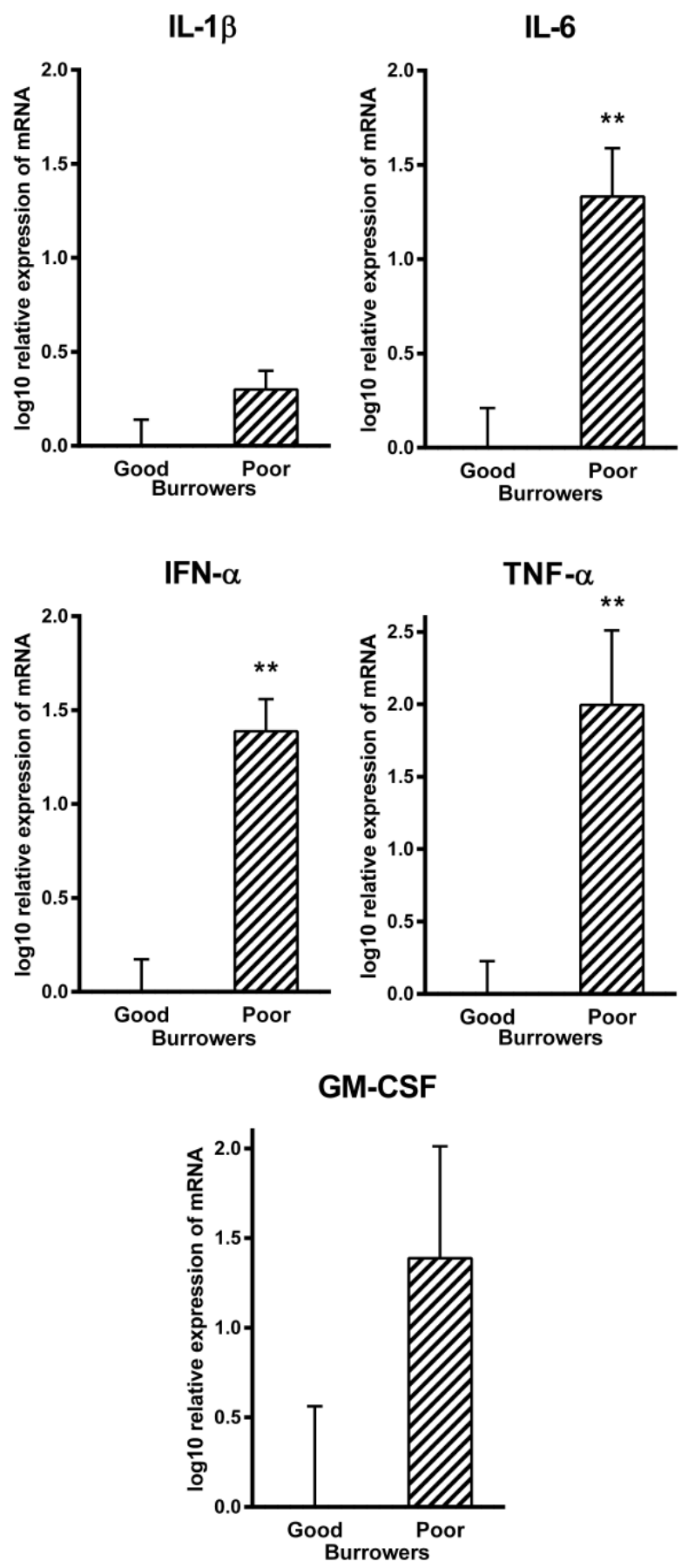

Fig. (4). Expression profile of cytokines genes in the Octodon degus model. Expression was measured using real time qPCR and the data normalized to $18 \mathrm{~S}$ rRNAgene expression as an endogenous control. Relative expression (RQ) was calculated by using the comparative Ct method with 'Control' O. degus (good burrower) samples used as the calibrator. The RQ value was calculated using the formula: $\mathrm{RQ}=2^{-\Delta \Delta \mathrm{Ct}}$. Assays were conducted in triplicate. Error bars represent \pm standard error of the mean. Data represents $O$. degus 'good burrowers' ( $\mathrm{n}=4)$ and $O$. degus 'poor burrowers' $(n=4)$. An unpaired, two-side t-test was performed on the data and significant differences in expression between 'good burrower' and 'poor burrower' ('Control' and 'AD-like') samples are shown as follows: all time points showed no significant differences in expression, $\mathrm{p} \geq 0.05$, except where shown significant, $*: 0.01<\mathrm{p}<0.05$, and $* *: p \leq 0.01$. pathway components were affected in the brains of good versus poor burrowers (Fig. 5). The targets examined were: $\mathrm{C} 1 \mathrm{q}$ (the first recognition subcomponent of the classical pathway), $\mathrm{C} 4$ (the protein involved in the generation of the C3 convertase in the classical pathway activation), C3 (the common target for $\mathrm{C} 3$ convertases from all three complement pathways i.e. classical, alternative and lectin pathways), C5 (the target of C5 convertase in all three pathways), and C9 (one of the major constituents of the membrane attack complex i.e. MAC). In addition, we also examined the differential levels of factor $\mathrm{H}$ (a negative regulator of the alternative pathway) and properdin (an upregulator of the alternative pathway). The data, as evident in Fig. (5), suggest a dramatic up-regulation of $\mathrm{C} 1 \mathrm{q}, \mathrm{C} 3, \mathrm{C} 4, \mathrm{C} 5$ and $\mathrm{C} 9$ in poor burrowers, suggesting that the classical pathway, via its interaction with $\mathrm{A} \beta$, may be the key to complement activation and subsequent inflammatory response in the brains of poor burrower animals.

\section{DISCUSSION}

\section{Burrowing Impairment in AD-Like O. degus}

The goal of the present investigation was firstly to evaluate an empirical method of showing if an $O$. degus had incipient AD-like neuropathology, as shown by a decrease in burrowing ability, a species-typical behavior that has proven sensitivity in other species (predominantly laboratory mice and rats but also spiny mice of three different species, hamsters, gerbils) [18-21]. We chose to use burrowing, as it seems to be the most sensitive of the species-typical behavior tests that we have developed [22].

A series of experiments demonstrated that burrowing in rodents is easily and simply measured, and is extremely sensitive to hippocampal lesions and scrapie (prion disease) infection [13-19]. To a reasonable extent, these conditions model $\mathrm{AD}$ : the hippocampus is one of the first brain areas to be affected in AD [29]. The hippocampus is well known to be crucial for spatial cognition in rodents, but its role in mediating species-typical behaviors was only formally declared recently [18]. Mice with near-complete lesions of the hippocampus showed that the effects of these cytotoxic lesions on burrowing capacity were consistent and reproducible. The histopathological damage to the hippocampus seen in affected $O$. degus [30] provides a physiological/anatomical correlate of their impaired burrowing, given the large burrowing impairments seen in mice with hippocampal lesions [16].

Hippocampal lesions profoundly impair many other species-typical behaviors in rodents. Such characterization has potentially wide-ranging implications, because many of these changes in species-typical behaviors are reminiscent of the impairments in activities of daily living (ADL) so characteristic of $\mathrm{AD}$ [31-32]. As discussed in an earlier publication [22], a mouse making a nest is more akin to an AD patient trying to make a bed, than a water-maze is to human learning and memory. Species-typical behaviors are not only a closer model of the behavioral disruption in $\mathrm{AD}$, their use might reveal therapies that treat activities of daily living, which are far more important than the memory deficits, since loss of the former requires carers to support the patient, whereas simple memory loss is less troublesome clinically. 

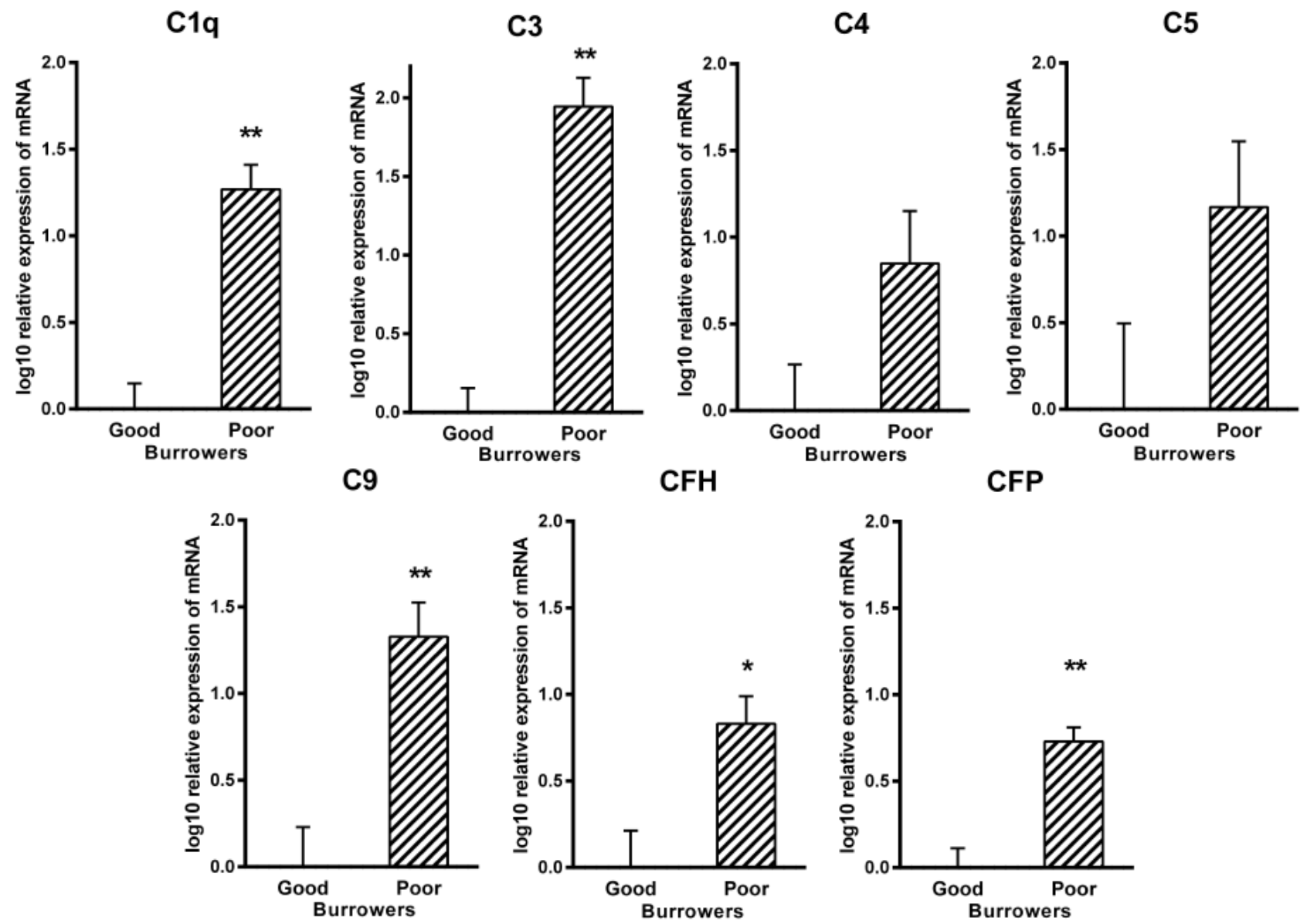

Fig. (5). Expression profile of complement component genes in the Octodon degus model. Expression was measured using real time qPCR and the data normalized to $18 \mathrm{~S}$ rRNA gene expression as an endogenous control. Relative expression (RQ) was calculated by using the comparative Ct method with 'Control' $O$. degus (good burrower) samples used as the calibrator. The RQ value was calculated using the formula: $\mathrm{RQ}=2^{-\Delta \Delta \mathrm{Ct}}$. Assays were conducted in triplicate. Error bars represent \pm standard error of the mean. Data represents $O$. degus 'good burrowers' $(\mathrm{n}=4)$ and $O$. degus 'poor burrowers' $(\mathrm{n}=4)$. An unpaired, two-side t-test was performed on the data and significant differences in expression between 'good burrower' and 'poor burrower' ('Control' and 'AD-like') samples are shown as follows: all time points showed no significant differences in expression, $\mathrm{p} \geq 0.05$, except where shown significant, *: $0.01<\mathrm{p}<0.05$, and $* *: \mathrm{p} \leq 0.01$.

Burrowing is used in this work in order to distinguish healthy (good burrowers) from AD-like (poor burrowers) $O$. degus. A $\beta$ deposits in brains of poor burrowers were confirmed by the presence of $A \beta_{1-42}$ peaks in MALDI-TOF spectra. $A \beta_{1-42}$ was merely used as a marker of an AD-like process in the $O$. degus brain. In particular, $\mathrm{A} \beta_{1-42}$ has been shown to play a pivotal role in the pathogenesis of $\mathrm{AD}$ due to its neurotoxic potential [33]. It has been suggested that soluble aggregates of $A \beta_{1-42}$ are more neurotoxic than the amyloid plaques and, in particular, that $A \beta_{1-42}$ is more amyloidogenic and more neurotoxic than $A \beta_{1-40}$ [34]. Immunoprecipitation combined with MALDI-TOF MS has previously been used to develop quantitative assays for $A \beta$ peptides in cerebrospinal fluid (CSF) [35].

From a behavior point of view, we are now developing a full battery of tests for $O$. degus, including a large number of cognitive tasks. However, the most affected cognitive process in AD is episodic memory. There is widespread skepticism whether animals excluding primates have this facility; hence, our interest in species-typical behaviors. The Claparede effect is a warning that current animal learning paradigms are inadequate to discover new $\mathrm{AD}$ treatments [22].
Our ultimate goal is to use burrowing as a re-usable screen to test putative AD treatments, primarily pharmacological applications. A great deal of time and money has been invested by pharmaceutical companies in this approach, but most of the preclinical work on animal models has employed learning and memory paradigms, such as the Morris watermaze. Burrowing is a quicker test than most of these paradigms, and moreover models another aspect of behavior that assails AD patients at an early stage in the disease process (loss of ADL). This has been summarized in an earlier publication [22]. The impairment of species typical behaviors, which has been shown to be characteristic of hippocampal dysfunction, complements the impairments in spatial learning and memory, which are also well-established effects of hippocampal lesions [36]. Moreover, O. degus (indeed all rodents) appear to find burrowing a rewarding activity; water-mazes are generally acknowledged to be stressful to nonaquatic animals, and stress can impair cognition.

\section{Neuroinflammation in AD-Like O. degus}

The role of inflammatory processes in AD is complex. There appears to be a clear link between neuroinflammation 
and neurodegeneration [23]. Accumulating evidence suggests that neuroinflammation, mediated by the brain's innate immune system, contributes to the AD neuropathology and exacerbates the course of the disease. However, there is no experimental evidence for a causal link between systemic inflammation or neuroinflammation and the onset of the disease [24].

Krstic and Knuesel propose that chronic inflammatory conditions cause dysregulation of mechanisms to clear misfolded or damaged neuronal proteins that accumulate with age, and concomitantly lead to tau-associated impairments of axonal integrity and transport. Such changes have several neuropathological consequences such as deposition of amyloid precursor protein in swollen neurites, generation of aggregation-prone peptides, and further tau hyperphosphorylation, ultimately resulting in neurofibrillary tangle formation and neuronal death [26]. In a nutshell, these arguments question the long-standing assumption that inflammation, particularly if it removes amyloid, has to be regarded as benign, and begin to probe the possibility that inflammation itself is contributing to junk protein deposition, to insulin resistance, to pathologic kinase activation, and from there to tangling.

The presence of $A \beta_{1-42}$ in the brain of poor burrowers is consistent with the raised levels of APP mRNA found in brains of AD-like O. degus in the present study. Excess APP production in $\mathrm{AD}$, which potentially leads to amyloidogenesis, is in part due to over expression of APP mRNA [37-38]. In human endothelial cells, a similar increase $(50 \%)$ of total APP mRNA was observed after treatment with human recombinant IL-1 $\beta$, suggesting a role of IL-1 $\beta$ in the neuronal mechanisms related to $\mathrm{A} \beta$ deposition in $\mathrm{AD}$ [39]. This suggests that inflammation has a role in amyloid deposition.

The transport and clearance of $A \beta$ peptides is mediated by Apolipoprotein E (ApoE), a major lipid transport protein of the central nervous system, implicating altered lipid homeostasis in the AD pathogenesis [40]. In the present work, raised levels of ApoE mRNA were found in the brains of poor burrowing $O$. degus, consistent with that found in the brains of AD patients, as assessed by quantitative PCR [38, 41].

The presence of neurotoxic $A \beta_{1-42}$ induces activation of the Nrf2 redox signaling pathway, known to be involved in oxidative stress, increasing intracellular reactive oxygen species production [42]. Consistent with this result, the mRNA level for Nrf2 was found to be significantly up-regulated in poor burrowers.

The levels of pro-inflammatory cytokines and complement proteins were examined in both groups of good and poor burrowing $O$. degus. There is clear evidence of a proinflammatory milieu in the brain extracts of poor burrowers compared to control good burrowers. The present results appear to confirm the hypothesis that inflammation has a role in amyloid deposition, and support $O$. degus as an integral model for AD.

Microglia, which are the resident macrophages of the CNS, perform immunosurveillance functions in the brain. Microglia, via their interaction with $\mathrm{A} \beta$, are capable of secreting pro-inflammatory cytokines including IL-1 $\beta$, IL-6, TNF- $\alpha$ and IFN- $\gamma$, as well as a range of chemokines [43-44]. Raised levels of these cytokines have been reported in AD brains [45]. In culture, $A \beta$ challenge to microglial cells can induce production of a wide range of pro-inflammatory soluble factors including cytokines and complement [46-47]. In addition to microglia, astrocytes and oligodendrocytes are likely sources of these pro-inflammatory factors. The most possible scenario in the $O$. degus AD-like brains is the activation of these cells in response to a varying level of aggregated $A \beta$ leading to generation of pro-inflammatory cytokines (and complement proteins; see below), which can impact upon amyloidosis, neurodegeneration, and cognition [45].

The complement system appears to be one of the key mediators of inflammation in neurodegenerative diseases [23]. Raised levels of the classical pathway components, together with components of the membrane attack complex (MAC) in the brains of poor burrowers, are suggestive of intrinsic endogenous production of complement proteins and possible interaction between $\mathrm{A} \beta$ and $\mathrm{Clq}[46,48]$. This interaction can first lead to the production of pro-inflammatory side products, $\mathrm{C} 3 \mathrm{a}, \mathrm{C} 4 \mathrm{a}$ and $\mathrm{C} 5 \mathrm{a}$, which can act as potent anaphylatoxins, recruiting infiltration in the CNS. The second major impact of the complete complement activation is the deposition of MAC at the senile plaques. Consistent with these notions, C1q and MAC can be co-localized with amyloid plaques [49]. In addition, expression of complement gene expression is up-regulated in the AD brain [50]. This heightened level of pro-inflammatory cytokines and soluble factors such as complement proteins are likely to be pathogenic in $O$. degus, as is the case in human $\mathrm{AD}$.

\section{CONCLUDING REMARKS}

The recent neuroinflammatory perspective on AD [24, 26] suggests why the transgenic animal models centered on the amyloid cascade hypothesis, might fall short of a representative analog to $\mathrm{AD}$.

The results presented in this work confirm a natural ADlike neuropathology in $O$. degus, which develops spontaneously with age, with similar characteristics to human AD at molecular, cellular and behavioral levels: neuroinflammation, oxidative injury, immune response, presence of $A \beta$ peptides in the brain, accompanied by a marked decrease in burrowing behavior. These characteristics put $O$. degus in a singular position as a natural rodent model for AD. The $O$. degus model offers the opportunity for investigating the ensemble of progressive neurodegenerative mechanisms in natural living animals from the early onset of the disease until its last stages.

Burrowing, as a non-invasive technique, could be used as part of the initial screening of a colony of $O$. degus prior to assessing pharmacological treatments. Since $O$. degus commonly live six years or more in captivity, and burrowing impairments can be seen at a relatively young age, this provides a long time window during which treatments of putative application for AD can be assessed. Burrowing is a noninvasive and sensitive tool that should allow exploration in vivo of some of the neuroprotective properties or memory enhancing effects of potential novel treatments for AD.

\section{CONFLICT OF INTEREST}

The authors confirm that this article content has no conflict of interest. 


\section{ACKNOWLEDGEMENTS}

We acknowledge Dr. Michael J. Hurley (Centre for Neurodegeneration and Neuroinflammation, Brain Sciences Division, Department of Medicine, Imperial College, London, UK) for critical reading of the manuscript. This research was funded by NEURO-DVI LLP (London, UK), by the Chilean National Commission for Scientific and Technological Research Grants 1090794 and 1140548 (to R.A.V.), by the Institute for Ecology and Biodiversity Millenium Scientific Initiative P05-002 and PBF-23-CONICYT (to R.A.V.), by Brunel University (London, UK) and by Fraunhofer Chile Research with the support of Innova-Chile CORFO (Project Code \#09CEII-6991). Research was conducted under permit No. 5193 issued by the Servicio Agrícola y Ganadero, Chile, with the supervision of the Ethics Committee of the Faculty of Sciences, Universidad de Chile.

\section{REFERENCES}

[1] Hampel H, Prvulovic D, Teipel S, Jessen F, Luckhaus C, Frolich L, et al. The future of Alzheimer's disease: the next 10 years. Prog Neurobiol 95: 718-728 (2011).

[2] Wimo A, Jonsson L, Bond J, Prince M, Winblad B. The worldwide economic impact of dementia 2010. Alzheimers Dement 9: 1-11 (2013).

[3] Ballard C, Gauthier S, Corbett A, Brayne C, Aarsland D, Jones E. Alzheimer's disease. Lancet 377: 1019-1031 (2011).

[4] Mayeux R, Stern Y. Epidemiology of Alzheimer disease. Cold Spring Harb Perspect Med 2: 1-18 (2012).

[5] Braidy N, Muñoz P, Palacios AG, Castellano-Gonzalez G, Inestrosa NC, Chung RS, et al. Recent rodent models for Alzheimer's disease: clinical implications and basic research. J Neural Transm 119: 173-195 (2012).

[6] Saraceno C, Musardo S, Marcello E, Pelucchi S, Di Luca M. Modeling Alzheimer's disease: from past to future. Front Pharmacol 4: 77 (2013).

[7] Vásquez RA. Vigilance and social foraging in Octodon degus (Rodentia: Octodontidae) in central Chile. Revista Chilena de Historia Natural 70: 557-563 (1997).

[8] Vásquez RA, Ebensperger LA, Bozinovic F. The influence of habitat on travel speed, intermittent locomotion, and vigilance in a diurnal rodent. Behav Ecology 13: 182-187 (2002).

[9] Inestrosa NC, Reyes AE, Chacón MA, Cerpa W, Villalón A, Montiel J, et al. Human-like rodent amyloid- $\beta$-peptide determines Alzheimer pathology in aged wild-type Octodon degus. Neurobiol Aging 26: 1023-1028 (2005).

[10] Ardiles AO, Tapia-Rojas CC, Mandal M, Alexandre F, Kirkwood A, Inestrosa NC, et al. Postsynaptic dysfunction is associated with spatial and object recognition memory loss in a natural model of Alzheimer's disease. Proc Natl Acad Sci USA 109: 13835-13840 (2012).

[11] Tarragon E, Lopez D, Estrada C, Ana GC, Schenker E, Pifferi F, et al. Octodon degus: a model for the cognitive impairment associated with Alzheimer's disease. CNS Neurosci Ther 19: 643-648 (2013).

[12] Castro-Fuentes R, Socas-Pérez R. Octodon degus: A Strong Attractor for Alzheimer Research. Basic Clin Neurosci 4: 91-96 (2013).

[13] Deacon RMJ, Raley JM, Perry VH, Rawlins JNP. Burrowing into prion disease. Neuroreport 12: 2053-2057 (2001).

[14] Contet C, Rawlins JNP, Deacon RMJ. A comparison of 129S2/SvHsd and C57BL/6JOlaHsd mice on a test battery assessing sensorimotor, affective and cognitive behaviors: implications for the study of genetically modified mice. Behav Brain Res 124: 33-46 (2001).

[15] Guenther K, Deacon RMJ, Perry VH, Rawlins JNP. Early behavioral changes in scrapie-affected mice and the influence of dapsone. Eur J Neurosci 14: 401-409 (2001).

[16] Deacon RMJ, Bannerman DM, Kirby BP, Croucher A, Rawlins JNP. Effects of cytotoxic hippocampal lesions in mice on a cognitive test battery. Behav Brain Res 133: 57-68 (2002).

[17] Cunningham C, Deacon RMJ, Wells H, Boche D, Waters S, PicancoDiniz C, et al. Synaptic changes characterize early behavioral signs in the ME7 model of murine prion disease. Eur J Neurosci 17: 2147-2155 (2003).

[18] Deacon RMJ, Rawlins JNP. Hippocampal lesions, species-typical behaviors and anxiety in mice. Behav Brain Res 156: 241-249 (2005).

[19] Deacon RMJ. Burrowing in rodents: a sensitive method for detecting behavioral dysfunction. Nat Protocols 1: 118-121 (2006).

[20] Deacon RMJ. Burrowing: A sensitive behavioral assay, tested in five species of laboratory rodents. Behav Brain Res 200:128-133 (2009)

[21] Deacon RMJ. Digging in Mice: Marble Burying, Burrowing, and Direct Observation Reveal Changes in Mouse Behavior. In (ed. Gould TD) Mood and anxiety related phenotypes in mice. From: Neuromethods 42. New York: Humana Press, pp. 37- 45 (2009).

[22] Deacon RMJ. A Novel Approach to Discovering Treatments for Alzheimer's Disease. J Alzheimer's Dis Parkinsonism 4: 142 (2014).

[23] Bonifati DM, Kishore U. Role of complement in neurodegeneration and neuroinflammation. Mol Immunol 44: 999-1010 (2007).

[24] Krstic D, Madhusudan A, Doehner J, Vogel P, Notter T, Imhof C. et al. Systemic immune challenges trigger and drive Alzheimer-like neuropathology in mice. J Neuroinflammation 9: 151-173 (2012).

[25] Shastri A, Bonifati DM, Kishore U. Innate Immunity and Neuroinflammation, Mediators Inflamm 2013: 342931(2013).

[26] Krstic D, Knuesel I. Deciphering the mechanism underlying lateonset Alzheimer disease. Nat Rev Neurol 9: 25-34 (2013).

[27] Kenagy GJ, Nespolo RF, Vásquez RA, Bozinovic F. Daily and seasonal limits of time and temperature to activity of degus. Revista Chilena de Historia Natural 75: 567-581 (2002).

[28] Vásquez RA, Grossi B, Márquez IN. On the value of information: studying changes in patch assessment abilities through learning. Oikos 112: 298-310 (2006).

[29] Small SA, Schobel SA, Buxton RB, Witter MP, Barnes CA. A pathophysiological framework of hippocampal dysfunction in ageing and disease. Nat Rev Neurosci 12: 585-601 (2011).

[30] van Groen T, Kadish I, Popovic N, Popovic M, Caballero-Bleda M, Baño-Otálora B, et al. Age-related brain pathology in Octodon degus: Blood vessel, white matter and Alzheimer-like pathology. Neurobiol Aging 32: 1651-1661 (2011).

[31] Potkin SG. The ABC of Alzheimer's disease: ADL and improving day-to-day functioning of patients. Int Psychogeriatr 14: 7-26 (2002).

[32] Reisberg B, Finkel S, Overall J, Schmidt-Gollas N, Kanowski S, Lehfeld $\mathrm{H}$, et al. The Alzheimer's disease activities of daily living international scale (ADL-IS). Int Psychogeriatr 13: 163-181 (2001)

[33] De-Paula VJ, Radanovic M, Diniz BS, Forlenza OV. Alzheimer's disease. Subcell Biochem 65: 329-52 (2012).

[34] Zhang YW, Thompson R, Zhang H, Xu H. APP processing in Alzheimer's disease. Mol Brain 4: 3 (2011).

[35] Gelfanova V, Higgs RE, Dean RA, Holtzman DM, Farlow MR, Siemers ER, et al. Quantitative analysis of amyloid- $\beta$ peptides in cerebrospinal fluid using immunoprecipitation and MALDI-Tof mass spectrometry. Brief Funct Genomic Proteomic 6: 149-58 (2007).

[36] Deacon RM, Glass L, Snape M, Hurley MJ, Altimiras FJ, Biekofsky RR, et al. NNZ-2566, a novel analog of (1-3)IGF-1, as a potential therapeutic agent for fragile $\mathrm{X}$ syndrome. Neuromolecular Med 17: $71-82$ (2015).

[37] Amara FM, Junaid A, Clough RR, Liang B. TGF- $\beta(1)$, regulation of Alzheimer amyloid precursor protein mRNA expression in a normal human astrocyte cell line: mRNA stabilization. Mol Brain Res 71: 42-49 (1999).

[38] Matsui $T$, Ingelsson M, Fukumoto $H$, Ramasamy K, Kowa H, Frosch MP, et al. Expression of APP pathway mRNAs and proteins in Alzheimer's disease. Brain research 1161: 116-123 (2007).

[39] Forloni G, Demicheli F, Giorgi S, Bendotti C, Angeretti N. Expression of amyloid precursor protein mRNAs in endothelial, neuronal and glial cells: modulation by interleukin-1. Mol Brain Res 16: 128-134 (1992)

[40] Couttas TA, Kain N, Daniels B, Lim XY, Shepherd C, Kril J, et al. Loss of the neuroprotective factor Sphingosine 1-phosphate early in Alzheimer's disease pathogenesis.Acta Neuropathol Commun 2:9 (2014).

[41] Liu CC, Kanekiyo T, XuH, Bu G. Apolipoprotein E and Alzheimer disease: risk, mechanisms, and therapy. Nat Rev Neurol 9: 106-118 (2013). 
[42] Jhang KA, Lee EO, Kim HS, Chong YH. Norepinephrine provides short-term neuroprotection against $\mathrm{A} \beta 1-42$ by reducing oxidative stress independent of Nrf2 activation. Neurobiol Aging 35: 24652473 (2014).

[43] El Khoury J, Luster AD. Mechanism of microglia accumulation in Alzheimer's disease: therapeutic implications. Trends Pharmacol Sci 29: 626-632 (2008).

[44] Walker DG, Kim SU, McGeer PL. Complement and cytokine gene expression in cultured microglial derived from postmortem human brains. J Neurosci Res 40: 478-493 (1995).

[45] Wyss-Coray T, Muckle I. Inflammation in neurodegenerative disease: a double-edged sword. Neuron 35: 419-432 (2002).

[46] Rogers J, Cooper NR, Webster S, Schultz J, McGeer PL, Styren $\mathrm{SD}$, et al. Complement activation by beta-amyloid in Alzheimer disease. Proc Natl Acad Sci USA 89: 10016-10020 (1992).
[47] Lue LF, Rydel R, Brigham EF, Yang LB, Hampel H, Murphy GM $\mathrm{Jr}$, et al. Inflammatory repertoire of Alzheimer's disease and nondemented elderly microglia in vitro. Glia 35: $72-79$ (2001).

[48] Kishore U, Gupta SK, Perdikoulis MV, Kojouharova MS, Urban $\mathrm{BC}$, Reid KB. Modular organization of the carboxy-terminal, globular head region of human $\mathrm{C} 1 \mathrm{q}$ A, B and C chains. J Immunol 17: 812-820 (2003).

[49] Fonseca MI, Kawas CH, Troncoso JC, Tenner AJ. Neuronal localization of $\mathrm{Clq}$ in preclinical Alzheimer's disease. Neurobiol Dis 15: 40-46 (2004).

[50] Blalock EM, Geddes JW, Chen KC, Porter NM, Markesbery WR, Landfield PW. Incipient Alzheimer's disease: microarray correlation analyses reveal major transcriptional and tumor suppressor responses. Proc Natl Acad Sci USA 101: 2173-2178 (2004). 